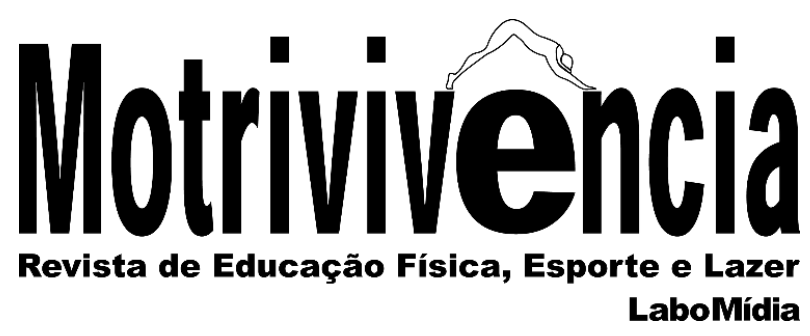

\title{
Tendências internacionais na Educação Física colombiana: algumas apropriações
}

\section{RESUMO}

Este artigo analisou a recepção, a partir dos anos 1970, de algumas perspectivas internacionais da Educação Física na Colômbia, representadas por nomes como Le Boulch, Parlebas, Cagigal, Kurt Meinel, etc. Metodologicamente, baseou-se no estudo das revistas "Educación Física y Deporte" e "Lúdica Pedagógica", bem como na realização de 16 entrevistas com importantes nomes da Educação Física colombiana. Os resultados indicaram as apropriações realizadas, destacando seus impactos teóricos na área.

PALAVRAS-CHAVE: Educação física;

Colômbia; Epistemologia
Karen Lorena Gil Eusse

Doutorado em Educação Física (UFES)

Programa de Pós-Graduação em Educação Física,

Universidade Federal do Espírito-Santo, Vitória,

Brasil

kalogil@yahoo.es

http://orcid.org/0000-0003-2625-3877

Felipe Quintão de Almeida

Doutorado em Educação (UFSC) Universidade Federal do Espírito-Santo,

Departamento de Ginástica,

Vitória, Brasil

fqalmeida@hotmail.com

${ }^{\circ}$ http://orcid.org/0000-0002-4056-5159

Valter Bracht

Doutorado em Filosofia (Oldenburg)

Programa de Pós-Graduação em Educação Física,

Universidade Federal do Espírito-Santo, Vitória,

Brasil

kalogil@yahoo.es

http://orcid.org/0000-0002-6810-3060 


\title{
International trends in the colombian Physical Education: some appropriations
}

\begin{abstract}
This article analyses the reception of some international perspectives of Physical Education in Colombia, occurred after the 1970's, represented by names such as Le Boulch, Parlebas, Cagigal, Kurt Meinel, etc. In methodological terms, the study was based on a analysis of the journals "Educación Física y Deporte" and "Lúdica Pedagógica", as well as on 16 interviews with important names of Physical Education in Colombia. The results showed the appropriations made, with emphasis on their theoretical impacts on the field.
\end{abstract}

KEYWORDS: Physical education; Colombia; Epistemology

\section{Tendencias internacionales en la Educación Física colombiana: algunas apropiaciones}

\section{RESUMEN}

Este artículo analizó la recepción, a partir de los años 1970, de algunas perspectivas internacionales de la Educación Física en Colombia, representadas por nombres como Le Boulch, Parlebas, Cagigal, Kurt Meinel, etc. Metodológicamente, se fundamentó en el estudio de las revistas "Educación Física y Deporte" y "Lúdica Pedagógica", así como en la realización de 16 entrevistas con importantes nombres de la Educación Física colombiana. Los resultados indicaron las apropiaciones producidas, destacando sus impactos teóricos en el área.

PALABRAS-CLAVE: Educación física; Colombia; Epistemología 


\section{INTRODUÇÃO}

Este artigo compõe a pesquisa desenvolvida no âmbito de uma Tese de Doutorado cujo objetivo foi investigar movimentos de crítica e renovação da Educação Física na Colômbia, produzidos a partir das décadas finais do século XX. ${ }^{1}$ No estudo das fontes que possibilitaram a construção daquela análise, tanto no caso das revistas "Educación Física y Deporte” (1979-2016) e “Lúdica Pedagógica” (1991-2017), mas, também, em relação às entrevistas realizadas com os 16 depoentes que colaboraram com a investigação, identificamos referência a autores, a conceitos ou a perspectivas internacionais de Educação Física que produziram uma renovação teórica no campo, especialmente a partir do final dos anos 1970. Este texto objetiva, deste modo, refletir sobre algumas apropriações que o campo da Educação Física colombiana fez de autores de outras regiões do globo, priorizando, aqui, as contribuições de José María Cagigal, da Espanha, dos franceses Pierre Parlebas e Le Boulch e de Cuba, com suas diversificadas influências.

Em relação às entrevistas, elas foram realizadas com 16 colaboradores, 15 colombianos e 01 professor alemão que trabalhou na "Universidad de Antioquia" por alguns anos. De posse de um roteiro prévio para guiar a conversação, o primeiro professor foi entrevistado no dia 16 de fevereiro de 2016. Com sua ajuda, mas, também, graças à leitura de textos disponíveis na revisão de literatura realizada, "chegamos" aos outros 15 entrevistados, sendo a última entrevista realizada em 15 de junho de 2018. Todas foram devidamente transcritas e, posteriormente, categorizadas e analisadas, procedimento que se balizou nas orientações da análise de conteúdo (BARDIN, 2011). Nossos colaboradores viveram, de distintas maneiras, o que chamamos, na Tese que anima este artigo, de crítica e renovação da Educação Física colombiana. Alguns ainda eram estudantes quando essa crítica se iniciou na direção descrita na Tese (final dos anos 1960), tornando-se, anos depois, professores das Universidades em que fizeram sua própria formação inicial. Outros vão conhecer este processo ao longo dos anos 1970 e 1980. Fizeram parte, de distintas maneiras, no processo de problematização da tradição instituída na disciplina. ${ }^{2}$

A análise de conteúdo foi novamente utilizada, mas, desta vez, no estudo dos periódicos "Educación Física y Deporte” e "Lúdica Pedagógica", publicações, respectivamente, do "Instituto de Educación Física de la Universidad de Antioquia" e da "Universidad Pedagógica Nacional". No caso de "Educación Física y Deporte", o periódico começou a ser publicado em 1979 e a análise foi realizada até o volume 35, n. 2 de 2016. No caso de "Lúdica Pedagógica", a primeira edição é de 1991. Após um vácuo de cinco anos, a segunda edição da revista é publicada em 1996. A

\footnotetext{
${ }^{1}$ Investigação financiada com bolsa de Doutorado pela FAPES (processo 71524754).

${ }^{2}$ Uma descrição mais detalhada dos depoentes pode ser obtida em Eusse (2020).
} 
investigação de suas páginas foi conduzida até o n. 25 de 2017. Escolhemos essas fontes pois são revistas com um ciclo de vida longevo e são publicadas por duas instituições tradicionais no âmbito da formação de professores de Educação Física. Além disso, seus números estão disponíveis em plataformas digitais, o que facilitou o acesso a todos os exemplares desde seus respectivos inícios.

Esses impressos são aqui entendidos como material privilegiado para a apreensão dos modos de funcionamento de um campo educacional, dando a ver discussões, problematizações e polêmicas que conformam uma área acadêmica e profissional. No caso específico deste artigo, essas revistas foram importantes pois permitiram estabelecer alguma comparação/contraponto entre aquilo que foi afirmado nas entrevistas e a repercussão da Educação Física cubana e das ideias de Cagigal, Parlebas e Le Boulch em dois dos principais veículos de transmissão de ideias e prescrições pedagógicas na Educação Física colombiana.

O artigo está organizado em 4 tópicos, seguido das considerações finais.

\section{CUBA: da inspiração política ao treinamento esportivo, da cultura física à didática do movimento}

A influência deste país insular, localizado no mar do Caribe, foi sentida de diferentes maneiras na Educação Física colombiana. Vários entrevistados, como E1 (2016), E3 (2016), E8 (2017), E9 (2017) e E12 (2017), dedicaram uma significativa parte da entrevista a relatar a importância dos intercâmbios acadêmicos existentes entre Cuba e Colômbia, principalmente as viagens à ilha: “[...] entrenadores, profesores universitarios, gestores deportivos, dirigentes deportivos, deportistas, estudiantes de Educación Física, monitores, van a Cuba a formarse" (E3, 2016) e "[...] estos intercambios fueron vitales para traer conceptos y referencias" (E12, 2017). O horizonte político comunista, o esporte, o conceito de cultura física e a tradução de literatura europeu-soviética foram os principais legados de Cuba para a Educação Física colombiana.

Sobre a influência política de Cuba, a professora E2 (2016) expressou que a Revolução Cubana representou uma inspiração para a mudança pretendida na Educação Física colombiana. Explicou que “[...] teníamos como esa influencia del cambio en el mundo, del socialismo y del comunismo, y queríamos hacer la revolución [...]. Realmente creíamos que ahí había algo y trabajamos con eso porque teníamos una muy fuerte influencia de la revolución cubana, del pensamiento cubano [...]". Segundo a interpretação de E3 (2016), o contato com Cuba impactou as mobilizações de resistência e revolução social. Essa relação atingiu

[...] la formación profesional, con el asunto de la intelectualidad, digámoslo, del campo, de la configuración del campo académico, porque con esta influencia 
cubana vienen también asuntos relacionados con la liberación, con la emancipación, con la resistencia, con la revolución urbana, con algunas manifestaciones políticas como el ejército de liberación nacional, como las milicias del ejército de liberación nacional en las ciudades, conexiones desde ahí con el movimiento estudiantil, con el movimiento profesoral, con el movimiento obrero, deporte y política [...]. La manifestación cubana viene más articulada a un asunto, según algunas lecturas, de intereses cubanos soviéticos por configurar un polo, un núcleo de sensibilización o de concientización política en América Latina.

E4 (2017), na mesma direção, entendia que o principal resultado da influência cubana na Educação Física colombiana foi político, em vez de teórico. A interlocução teve uma forte preocupação em “[...] seducir a las personas hacia el comunismo, hacia el marxismo”. E13 (2017) reconheceu que o intercâmbio com Cuba o "[...] aproximó conceptualmente mucho a la izquierda fundamentada, al catecismo del socialismo". O professor E1 (2016), um dos protagonistas desse intercâmbio com Cuba, disse que, em 1977, um grupo de mais ou menos 20 professores viaja para a Habana financiados por Coldeportes. ${ }^{3}$ Segundo a mesma entrevista, esse grupo de profissionais viajou esperando encontrar uma Educação Física "revolucionária”, como era o país em relação às questões ideológicas; existia neles o "ideal del socialismo", mas, em palavras textuais do professor E1 (2016): “[...] paradójicamente, cuando nosotros fuimos a Cuba, encontramos que la Educación Física era militarista”. Na compreensão de E2 (2016), a Educação Física em Cuba “[...] tiene um corte marcial, de formaciones, fines y de deporte fuerte, de una herencia muy militar". Além de militarista, uma Educação Física focada no esporte, apontou E9 (2017), outro dos beneficiados com o intercâmbio, que lembra que, na viagem, receberam “[...] una formación en entrenamiento deportivo de alto rendimiento orientado al baloncesto y muy buena formación, pues en ese momento los cubanos eran número uno en la formación en Suramérica".

Nem todos os colegas que foram a Cuba, especialmente nos intercâmbios após os anos 1970, tinham como interesse principal os temas políticos, visto que estavam mais preocupados em aprender sobre o sucesso esportivo do país:

[...] fueron a Cuba, algunos fueron a estudiar en la Fajardo, a estudiar un poco algún tema del entrenamiento deportivo y lograr eficiencia en el deporte, la aspiración de muchos era convertirse en entrenadores. [...] incluso yo participé en el Congreso Panamericano de Educación Física que se hace en el año 86 en la Habana, fue un movimiento que de aquí fueron como unas ciento y pico de personas pero pues, la expectativa era como en ese momento, los resultados cubanos en deporte y la gente iba era con esa mirada $[\ldots](\mathrm{E} 8,2018)$.

\footnotetext{
${ }^{3} \mathrm{O}$ "Departamento Administrativo del Deporte, la Recreación, la Actividad Física y el Aprovechamiento del Tiempo Libre" (conhecido como Coldeportes) é a entidade reguladora do esporte na Colômbia, fundado em 1968 e atuante ainda hoje.
} 
Na mesma linha de compreensão, relatou E5 (2017) que Cuba foi referência para os estudos em treinamento esportivo, uma vez que

[...] a través de Cuba recibimos todas las teorías del entrenamiento, pudimos vivir experiencias de sus maestrías que hacían en Rusia, gente que se fue a formar allá a Cuba y que aprendió todas las técnicas y todas las cosas de la periodización del entrenamiento, planificación del entrenamiento, el papel de la fuerza en los resultados deportivos, un poco ese modelo del desarrollo deportivo cubano, el tema de la selección deportiva que fue tan masivo, eso llegó a través de Cuba [...]. La Escuela Nacional del Deporte traía por ejemplo a un jugador de la selección olímpica de voleibol y allá enseñaba voleibol por muchos años.

Acrescentou E15 (2018) que várias expressões do esporte de rendimento inspirado em Cuba foram implementadas nas práticas pedagógicas da disciplina na Colômbia, como “[...] el tema de los juegos escolares, eso lo cogió Coldeportes, el tema de los festivales escolares, eso lo cogió Coldeportes entre el 80 y el 90 y muchas de esas cosas todavía se implementan”.

Outro modo de ver a "presença" cubana na Educação Física colombiana é por meio do conceito de "cultura física". Segundo Sánchez e Barroso (2015), tal nomenclatura foi compreendida, em Cuba, como um "momento da cultura" para o aperfeiçoamento do potencial biológico e espiritual do homem em relação à prática de atividade física. Aqueles autores explicaram que os profissionais da área "[...] Deben promover el Deporte como organismo ideológico del estado que contribuye a la edificación y consolidación del país [...]". Para Molina e Ossa (2009, p. 68), "Este paradigma caracterizava a los países socialistas los cuales tienen como índices más importantes de la cultura física, el estado de salud y el nível de desarrollo físico de la población".

Nos primeiros editoriais da revista "Educación Física y Deporte", bem como em artigos aí publicados, não raro foi possível identificar a menção a esse conceito, embora sem muita explicação do seu sentido para Colômbia. Pinillos (2003) descreveu que a presença da referida concepção na Educação Física colombiana cumpriu um papel nas reflexões sobre o estatuto do saber profissional, sendo também importante nos debates a respeito da identidade acadêmica e do objeto de estudo da disciplina. Para ele, o principal resultado de seu uso foi a ampliação da diversidade de práticas que passaram a englobar a expressão "Educação Física", que deixou de se referir, apenas, ao campo escolar. O autor (2003) publicou parte de um rascunho, do ano de $1988,{ }^{4}$ anunciando a criação da

\footnotetext{
${ }^{4}$ Neste mesmo ano, a revista do Instituto, em uma das suas edições, publicou a programação do "III Congreso Departamental de Educación Física", em Antioquia, a ser realizado em 1989, cujo título era "Cultura Física: perspectivas de desarrollo en Antioquia" (CALENDARIO, 1988, p. 107).
} 
"Escola de Cultura Física" em substituição ao "Instituto Universitário de Educación Física", da Universidade de Antioquia, em Medellín:

La Educación Física, como máxima expresión de la Cultura Física de un país, constituye un proceso pedagógico dirigido a la sociedad, cuya base debe ser eminentemente biológica, higiénica y social. Constituye igualmente, manifestaciones de la Cultura Física, la Recreación, y el Tiempo Libre, el Deporte como fenómeno social, la Actividad Física Laboral y la Actividad Física como medio de Rehabilitación, entre otras (CONSEJO, 1988 citado por PINILLOS, 2003, p. 56).

Reforçou E1 (2016) que, depois de voltar da experiência de intercâmbio em Cuba, ficaram convencidos de que a Educação Física devia ser chamada, na Colômbia, de "cultura física" “[...] tuvimos mucho tiempo discutiendo el nombre porque algunos queríamos que se llamara Instituto de Cultura Física y no Instituto de Educación Física. Entonces todo ese asunto contribuyó a que se hiciera una discusión sobre el verdadero sentido de la Educación Física en Colombia”.

Pinillos (2003) argumentou que, apesar de não se efetivar tal proposta, foi base inspiradora para o desenho do modelo de ampliação das práticas pedagógicas na formação de licenciados em Educação Física da Universidade de Antioquia. Desse modo, "La docencia en el ámbito escolar no sería el único fin de las instituciones formadoras de profesionales y las prácticas profesionales se diversifican a otros ámbitos de educación no formal, como la salud, la Recreación, el Entrenamiento Deportivo y el trabajo con Discapacitados” (PINILLOS, 2003, p. 300). Pinillos (2003) também discutiu, nessa publicação, que a diversidade de enfoques pressupostos pela noção de "cultura física" dificultou definir, com clareza, qual seria, de fato, o objeto de estudo da Educação Física. Assim, tal influência "[...] se convirtió en un reto para la Educación Física, tanto a nivel disciplinar, como profesional, pero al mismo tiempo amplio la crisis sobre el objeto de estudio [...]" (PINILLOS, 2003, p. 302).

Outro impacto cubano no campo da Educação Física colombiana está relacionado à tradução de literatura escrita em línguas que não o castelhano. Por exemplo, “[ ...] a través de Cuba se ha llegado a difundir mucha literatura alemana y soviética de gran impacto científico" na Colômbia (FACULTAD, 2002, p. 6).

Entende Pinillos (2007, p. 22) que a eleição, nos anos 1980, do "movimento" como objeto de estudo da Educação Física foi motivada, entre outros, por Kurt Meinel, cujas ideias ingressaram no país "[...] gracias a los intercâmbios realizados com Cuba, desde finales de la década de los setenta”. Facultad (2002, p. 4), por sua vez, viu o autor como um dos dois mais influentes na Universidade Pedagógica Nacional, na década de 1980, em sua procura por fundamentação teórica 
para a disciplina: "Una propuesta resulta interesante y fundamentada en esta etapa: la de Kurt Meinel. Parece tratarse de una didáctica del movimiento, pero en realidad es toda una teoría del movimiento para los ámbitos de la EF y del deporte, con fundamentación ideológica”. Chinchilla (2002, p. 2), anos antes desta publicação, já mencionava a importante influência de "Didática do Movimento" para o "desarrollo científico de la educación física" colombiana, obra em que "el filósofo alemán Kurt Meinel expone el papel del movimiento y del lenguaje en la estructuración del pensamiento, y el desarrollo de las fuerzas del trabajo en los procesos de socialización”. Além disso, destacou, anos depois, que esta obra se encontrava respaldada em um enfoque do "materialismo histórico" (CHINCHILA, 2005, p. 107).

Ainda sobre a obra de Meinel, o professor E1 (2016) relatou que

Fuimos a Cuba y encontramos una literatura que venía de Alemania oriental, que era la Alemania comunista, entonces ahí, por ejemplo, el texto que nosotros trabajamos era 'Didáctica del Movimiento'. Un texto muy bueno de Kurt Meinel. Todo eso era muy técnico, pero como venía de un país comunista nosotros lo aceptábamos como que era muy bueno y alrededor de toda esta literatura, pues de lo oriental, de lo de [...] Alemania oriental, estaba ligada la literatura pedagógica de Rusia, de la Unión Soviética en esa época.

Informou E5 (2017) que, no início do contato com a obra de Meinel, o interesse era mais ideológico ou político, mas, posteriormente, ela teve um uso mais teórico, “[...] como desde conceptos básicos de la calidad de movimiento, el concepto de motricidad, cosas de ese estilo, un poquito más temática de la Educación Física”. Para E2 (2016), “[...] fue muy importante para nosotros Meinel y trabajamos mucho toda esa teoría del movimiento [...]” e E10 (2017): “[...] me leí didáctica del movimiento de Kurt Meinel [...] porque nosotros en esa época fuimos muy influenciados por la literatura cubana y por la literatura soviética". E13 (2017), por sua vez, apontou que desde o "[...] movimiento humano hubo una parte también muy fuerte de Meinel, Kurt Meinel, de la Alemania democrática, estoy hablando de comienzos de los 80, esas tendencias tuvieron mucha fuerza". E14 (2017) também entendeu que "Didactica del Movimiento de Meinel" foi um livro chave para compreender o debate epistemológico na Colômbia.

Estes relatos a respeito de Meinel evidenciam, por sua vez, as diferentes recepções de sua “obra” na Educação Física colombiana. Uns o destacaram como pertencente a uma literatura vinculada ao marxismo comunista, vendo seu trabalho como representante de uma perspectiva crítica de Educação Física. Outros enfatizaram sua importância para as questões didáticas. Houve aqueles, também, que ressaltaram sua relevância para os temas epistemológicos e para o 
desenvolvimento de uma teoria do movimento. Foi múltipla, portanto, a recepção de Meinel e da própria perspectiva cubana de Educação Física em território colombiano.

\section{PSICOMOTRICIDADE: uma alternativa ao cientificismo e ao esporte na Educação Física}

Talvez a Universidade Pedagógica Nacional, de Bogotá, tenha sido o lugar que mais recebeu influências dessa tendência internacional de Educação Física, em especial dos escritos de Jean Le Boulch. De acordo com o relato de E11 (2017), “[...] la mayor fuerza que tuvo Le Boulch fue en Bogotá [...] Le Boulch les dio muchas pistas para pensar una Educación Física como más en la infancia, pues primaria, eso también se ha desdibujado. Bogotá para mí fue clave para este autor”. Descreveu Pinillos (2011, p. 13) que o professor Héctor Peralta, então docente daquela Universidade,

[...] en el año de 1973 recibió en Francia un curso con Jean Le Boulch y trajo a Colombia el libro de la Educación por el movimiento (Le Boulch, 1970), visión de la Educación Física que fue difundida por Peralta en el país en diferentes cursos de capacitación, debido a que en su opinión el texto de Le Boulch se convirtió en un aporte valioso para fundamentar la Mirada de la Educación Física que se tenía en aquel entonces, básicamente desde el punto de vista de la Gimnasia.

Ainda em 1973, a referida instituição promoveu uma pesquisa sobre a tendência, em que se pretendia determinar aspectos da psicomotricidade, como esquema corporal e ajuste postural, em alunos das primeiras séries de ensino (VACA, 1998, p. 92). Depois dessa experiência, a coordenadora da pesquisa, a psicóloga María Teresa Velázquez, ofereceu a cátedra "Psicomotricidade" para a formação de professores de Educação Física na Universidade. Sobre o início dessa corrente no país, lembrou E5 (2017) que a professora María Teresa Velázquez

[...] viene a investigar y a pedir unos favores sobre la grafía de los niños relacionada con la motricidad de los niños, entonces necesita unos implementos de Educación Física y entonces esta profesora hace unos talleres y unos trabajos para examinar la manera en que escriben los niños, vincular la motricidad, y los de Educación Física la invitan a una conferencia, luego la invitan a un curso y finalmente la psicomotricidad se convierte en materia obligatoria. En el año 76 que yo entré a la universidad era opcional y como era opcional la vi en el primer semestre porque no teníamos como cupos, no sé qué pasó con los horarios entonces nos dieron la opción de estudiar motricidad primer semestre. Fue tan fuerte su influencia que después se volvió materia obligatoria y se volvió como en el espíritu con el que un licenciado debía trabajar, entonces uno debía trabajar esquema corporal, las conductas motrices de base que son la coordinación y el equilibrio, la lateralidad, etc. $\mathrm{O}$ sea, todas las nociones básicas de la psicomotricidad se volvieron la estructura de trabajo y especialmente en básica primaria para los licenciados en Educación Física [...] y termina eso siendo un eje fundamental de la 
formación de licenciados, tanto que en el 83, en el plan nacional de Educación Física colombiano aparecen apuntes de la clase de María Teresa Velázquez, era una bibliografía.

Também se referindo à professora Velázquez, reconheceu E15 (2018) que

En nosotros tuvo mucha influencia una señora de la Universidad Nacional que había estado en Francia y había estudiado con Le Boulch, que se llama María Teresa Velázquez. Esa señora marcó un hito porque nosotros la trajimos varias veces invitada a la Surcolombiana y ella como que mostró otro camino de la Educación Física y entonces mostró el camino de la Educación Física con enfoque psicomotor y fue lo que influyó mucho para que nosotros planteáramos alternativas de programas y como yo era profesor de colegio entonces a mí se me ocurrió que había que trabajar programas de Educación Física para la escuela y el colegio, o sea para la primaria y la secundaria [...] y logramos publicar unos programas que marcaron un hito en Colombia.

Wilches, Tuero e Álvarez (2012, p. 1039) afirmaram que

De Jean Le Boulch se difundió en especial manera su texto Hacia una Ciencia del Movimiento Humano, una traducción del documento original en francés editada en 1971, y reeditada en 1989 en español. Sus tesis sobre la significación del movimiento humano como modo de expresión y sus explicaciones sobre la transitividad del movimiento, junto con las primeras ideas que se conocían sobre el cuerpo - el paso del cuerpo objeto al cuerpo propio y su desarrollo como 'esquema corporal' desencadenaron una serie de incorporaciones teóricas en los discursos circulantes y en las distintas clases de la Facultad.

Da mesma forma, Facultad (2002, p. 3) apresentou a psicomotricidade como uma das correntes mais influentes da Universidade Pedagógica Nacional na década de 1980, detalhando que foi a base da prática docente na época:

Lo cierto es que la psicomotricidad se instaló como asignatura específica y obligatoria de la licenciatura, y como orientación preferencial de la práctica docente en el Departamento de la época. No se concebía un profesional de la EF que no planeara y realizara su trabajo con los elementos conceptuales de la psicomotricidad.

A pesquisa de Pinillos (2003) registrou o fortalecimento dessa teoria a partir de então, citando a renovação curricular de 1983, em que a psicomotricidade se apresentou como referência para a construção de conteúdos para o ensino da disciplina nas primeiras séries. De igual maneira, mencionou a elaboração dos "lineamientos curriculares" para a área da Educação Física no ano 1984, documento formulado por profissionais colombianos que tomam os conhecimentos da psicomotricidade como referência. Também relembrou o autor a elaboração, em 1985, no Estado do Huila, de um manual para o ensino da disciplina nas primeiras séries, sustentado pela corrente e 
coordenado pelos professores Carlos Bolívar e Hipolito Camacho, “[...] experiencia que fue tenida en cuenta para formular los contenidos de la básica primaria por parte del Ministerio de Educación Nacional" (PINILLOS, 2003, p. 265). O autor também citou outras referências importantes para o ensino da disciplina na década de 1990, como o "Manual práctico para el desarrollo psicomotor del escolar", de Rosario González, de 1993, "Manuales Educación Física Preescolar" (1994) e “Educación Física, Infancia y Niñez” (1996), ambos de Jairo Arenas Acevedo.

Wilches (2012), com semelhante compreensão, ratificou que essa perspectiva serviu de base referencial para a formulação de guias práticos para professores de escola na Colômbia, ressaltando que “[...] la Psicología tenía mucha influencia en ese momento en la Educación, por el tema del desarrollo de la inteligencia y por las propuestas piagetianas que comenzaban a determinar la mirada educativa en el país [...]" (WILCHES, 2012, p. 159).

Continuou dizendo o autor que a presença da psicomotricidade na área refletia, também, um esforço que “[...] aporta entonces a la Educación Física un carácter científico, que se anhelaba y le otorgaba reconocimiento a la disciplina en el ámbito universitário" (WILCHES, 2012, p. 157). Com a psicomotricidade, ficava explícita a relação "[...] entre el pensamiento y el movimiento, con carácter de cientificidad", apresentando-se "[...] como una solución a las críticas que se le hacían a la Educación Física por sus reducidos aportes en dicha dimensión de la formación intelectual" (WILCHES; TUERO; ÁlVAREZ, 2012, p. 1036). Em outro estudo, Wilches (2001) analisou os "lineamientos curriculares" da Educação Física do ano 2000, oportunidade para concluir que tais "lineamientos" tomavam, outra vez, a psicomotricidade como uma das influências epistemológicas mais importantes na discussão sobre o objeto de estudo da Educação Física na Colômbia.

Ao mesmo tempo em que a psicomotricidade foi adotada no país como uma solução ao problema da falta de cientificidade, "aparece”, também, oferecendo uma nova orientação marcada por um argumento de crítica à tradição esportivista que caracterizava o campo. Comentou o professor E3 (2016):

[...] hay una cosa interesante y es que en esos años 1960, 1970, un poco eso empieza a debilitarse [enseñanza deportiva] por una movida que se configura, yo diría más por influencia española e influencia francesa o si se quiere influencia francesa por la vía española. Llegan libros, hay gente que va a estudiar a Europa, a España, a Francia y hay una movida psicomotriz y viene una tensión entre la movida psicomotriz y la movida deportiva como expresiones que intentan ganar cuerpo en los discursos de la pedagogía escolar o de la Educación Física escolarizada. Esa tensión se da entre los años 1960 y 1980, entre una corriente psicomotricidista apoyada en influencias que tienen que ver con Piaget y otras fuentes. 
Com um raciocínio semelhante, E15 (2018) colocou a psicomotricidade em uma contraposição ao esportivismo, ao dizer que:

Hasta ahí digamos, hasta el 80, pudiéramos decir o yo puedo decir, según mi apreciación, que el enfoque fue eminente deportivo en la Educación Física colombiana en todas las esferas, pero a partir del 80 comienza en Colombia a ser permeada por nuevas perspectivas de la Educación Física, una muy fuerte en Colombia fue la educación psicomotriz, la 'tendencia psicomotriz' que llamamos algunos. Entonces ya se lee a Ajuriaguerra, ya se lee a Picq y Vayer pero fundamentalmente se lee a Le Boulch que tenía dos características, primero que era licenciado en Educación Física o había sido profesor de Educación Física y médico y que escribía un poco sobre una Educación Física con enfoque psicomotor y planteó digamos un método psicocinético que todos conocimos por allá en la década del 80 y eso influyó mucho la Educación Física en Colombia, esa tendencia psicomotriz, a tal punto que el libro que nosotros publicamos para la Educación Física en primaria en el año 89 si no estoy mal, 85-89, es un libro eminentemente influenciado por esa tendencia, psicomotricidad.

Contra o esportivismo presente no campo, a psicomotricidade foi compreendida como uma forma de desenvolver capacidades como a inteligência, a comunicação, a afetividade, a sociabilidade e a aprendizagem por meio da motricidade (PINILLOS, 2011). Ao mesmo tempo, considerava o ser humano como uma unidade psicossomática conformada pela psique (o cognitivo) e a motricidade, “[...] planteando la concepción de un 'cuerpo pensante', 'educación del movimiento y por el movimiento', en contraposición a las teorías mecanicistas - biologistas, de la educación 'para' el movimiento que hasta ese momento direccionaban el hacer de la disciplina" (BENJUMEA, 2004, p. 6). Seria objetivo da Educação Física, assim compreendida,

[...] el dominio del cuerpo, que corresponde con el desarrollo de las funciones psicomotrices. La Educación Física debe equilibrar el exceso de materias intelectuales del sistema educativo, otorgando a la enseñanza suficiente espacio para la educación del cuerpo, y su finalidad es brindar el desarrollo de las aptitudes motrices y psicomotrices en relación con los aspectos afectivos, cognitivos y sociales de la personalidad (GALLO, 2010, p. 140).

Esta importante influência para a Educação Física colombiana ainda parece ter uma forte penetração na Educação Física do país, a julgar pelo que indicam Gracia (2006), Patiño e Díaz (2009), Mosquera (2010), Gallo e Urrego (2015) e Almeida, Eusse, Silva (2018).

\section{Pierre Parlebas e a Educação Física como a pedagogia das condutas motrizes}

Pierre Parlebas desenvolveu a proposta da "praxiologia" como "ciência da ação motriz". A lógica interna das ações motrizes foi tratada como o objeto de estudo dessa ciência. A Educação Física seria a encarregada da pedagogia das condutas motrizes, ressaltando, assim, o caráter 
pedagógico da disciplina. $\mathrm{O}$ autor insere-se na corrente da sociomotricidade, referente a uma motricidade de relação, à dimensão social da conduta motriz (GALLO, 2010; PARLEBAS, 19921993). "En la sociomotricidad hay un intento por fundamentar teóricamente la Educación Física, alejándola tanto de un reduccionismo biológico, de una educación del movimiento, como de un reduccionismo psicológico, de una educación a través del movimiento" (GALLO, 2010, p. 229). ${ }^{5}$

Na opinião de E3 (2016), a presença de Parlebas é um desdobramento da corrente psicomotricista, mas, nesse caso, muito mais enfocada no plano sociológico:

Yo diría que hay una transformación de esa perspectiva psicomotricista a unas influencias un poco más relacionadas con asuntos sociológicos, con asuntos un poco provenientes no sé si es de la lingüística, de la semiología. Aquí la encarna la influencia de Pierre Parlebas. La lógica interna de los juegos, el valor pedagógico de los juegos y con Parlebas, que es un poco la continuación, desde mi modo de entender, de esa movida psicomotricista.

Nesta mesma compreensão, comentou E1 (2016) a respeito da influência de Parlebas no país:

Parlebas es otro capítulo importante. Cuando nosotros conocimos a Parlebas, lo conocimos a través de Cuba. Él trabajaba toda la parte de la sociomotricidad, lo que era lo sociomotriz. Yo empecé a trabajarlo como en 1985 más o menos. Como en 1985 más o menos que lo empezamos a conocer por toda la parte del enlace con lo social. Entonces cuando hablamos de la sociomotricidad, entonces aparece Pierre Parlebas y empezamos con ese asunto.

Corroborando a opinião de E1, E15 (2018) informou que Parlebas começou a circular mais a partir de meados da década de 1980, mas que se transformou em uma impactante referência na década seguinte, ${ }^{6}$ com a presença do autor em um evento acadêmico no país, argumento que é reafirmado por Wilches (2012). Chinchilla (1998, p. 2) também destacou a presença do autor no “XIII Congreso Panamericano de Educación Física”, realizado em Bogotá, no ano 1991, em que se desenvolveu, entre outros, o tema do trabalho interdisciplinar da Educação Física, dentro de uma compreensão de disciplina com uma "pertinencia propia", motivo pelo qual não se deveria impor

\footnotetext{
${ }^{5}$ Diz Uribe (1998) que Parlebas define sociomotricidade em relação aos processos de adaptação social ou à comunicação que se apresenta no desenvolvimento da motricidade. O autor colombiano usou Parlebas para tratar dos benefícios do desenvolvimento motriz na formação dos sujeitos, em que justamente a sociomotricidade joga um papel indispensável. Ao mesmo tempo, Chinchilla $(2002$, p. 2) valeu-se do conceito de Parlebas para definir o tema da cultura política no contexto da sua pesquisa. Aqui, "La sociomotricidad explica las diferentes normas, roles, prescripciones, que producen las acciones motrices de los grupos sociales".

${ }^{6}$ A revista "Educación Física y Deporte" publicou, na edição 14-15, do ano 1992-1993, uma tradução de um artigo do autor, chamado "Didáctica y lógica de las actividades físicas deportivas". Apesar de sua crescente influência, foi o único artigo de Parlebas publicado nas páginas dos dois periódicos aqui estudados.
} 
“[...] la lógica, los procedimientos y aún los mismos objetos de otras disciplinas". Na mesma linha de compreensão, Mosquera (2010, p. 119) entende que

En los primeros años la tendencia de la praxeología motriz fue conocida en nuestro país por la asistencia de Parlebas al XIII Congreso Panamericano de Educación Física (1991) y más reciente en el Encuentro de Epistemología y Enseñanza de la Educación Física (2007), eventos que se realizaron en Bogotá.

Sobre o objeto de estudo proposto, comentou E5 (2017) que Parlebas "[...] viene con una visión distinta pues también nos va a influir, entonces no es el movimiento, es algo más, es el hombre que se está moviendo entonces empiezan a aparecer otras cosas”. Na mesma linha, lembrou E10 (2017) que “[...] llegó la alimentación de Parlebas, que nos dio muchos elementos en torno a la praxiología motriz, eso nos direccionó a otras órdenes, entonces yo creo que hay una ruptura". Ao mesmo tempo, E15 (2018) entendia que Parlebas "plantea la praxiología motriz, la ciencia de la acción motriz y plantea un discurso bien alternativo para la Educación Física y esa influencia llega a Colombia [...]". Tais relatos, desde o contexto de Bogotá, Medellín e Huila, respectivamente, descrevem uma ruptura ou mudança na terminologia e compreensão do objeto para o campo influenciado pela proposta do autor (BOLÍVAR, 1991; WILCHES, 2012).

A professora E11 (2017) afirmou ter estudado o autor e realizado uma entrevista com ele para sua Tese de Doutorado. Segundo contou,

Parlebas ha venido mucho a Colombia, lo han traído hasta acá al Instituto mucho y todavía lo traen mucho. Entonces, ¿qué pasa con Parlebas? Que Parlebas, a mí me parece, propone como dos cosas, uno la praxiología motriz como un asunto más como de preocupación más de ciencia, como en esa línea de hacer análisis más serios del deporte, de los juegos, bueno toda esa clasificación que él se inventa y lo otro como pedagogía de las conductas motrices, entonces esto es para la Educación Física y esto es para la praxiología motriz, él tiene muy claro eso, pero a la hora de pensar las conductas motrices en el contexto escolar pues ya ahí si es como ¿uno qué hace con eso?, a la final siempre recae como en el deporte o en esos juegos y la praxiología motriz como tal, como una forma de conocimiento para saber ciertas cosas que les interesa a los del deporte, la clasificación y toda esas vainas que, todos esos juegos y todas esas cosas, todas esas lógicas internas.

A definição da Educação Física proposta por Parlebas, desde a compreensão de que "La Educación Física posee su sello distintivo como disciplina definida, enseñanza, enmarcada dentro de un sistema educativo" (PARLEBAS, 1992-1993, p.18), serviu de referência teórica para vários nomes importantes do debate epistemológico no país andino, como Bolívar. Justamente esse autor ofereceu uma síntese dos aspectos que considera mais importantes do pensamento de Parlebas: 
1. Un objeto de estudio de la Educación Física, las conductas motrices, como distintivo original al interior de la pedagogía. Conducta motriz entendida como un comportamiento integral, de base práctica o motora, que articula en el sujeto emociones, sentimientos, pensamientos, etc., y expresiones concretas externas; al tiempo que se establecen relaciones sociales de comunicación específicas. 2. Por su carácter pedagógico, la Educación Física, si aspira a una misión exitosa, ha de inscribirse en un proyecto interdisciplinar con las demás áreas de la educación. 3. La necesidad de construir una nueva ciencia, praxeología motriz, cuyo ámbito y misión no se limite a la escuela ni a la educación (campo de la Educación Física) sino al estudio de la acción motriz, entendida esta última como una categoría conceptual más amplia que la de conducta motriz, referida: 'Al proceso de realización de las conductas motrices de uno o varios sujetos actuando en una situación motriz determinada'; en donde el análisis de la lógica interna de las situaciones motrices constituye el eje de comprensión de las acciones motrices. Entendiéndose por lógica interna de la situación motriz, la estructuración sistémica de, por ejemplo un deporte, que regula el desempeño de la acción misma, al controlar espacios, tiempos, contactos personales, etc. 4. La relación de interdependencia y provecho mutuo entre Educación Física y ciencia de la acción motriz, en el mismo sentido de la relación existente entre enseñanza de la física y la ciencia de la física, o la enseñanza de la lingüística y la ciencia de la lingüística (BOLÍVAR, 1991, p. 14-15).

Relacionado a essa posição, Chinchilla (2005) usou o autor como referência para defender a ideia de que a Educação Física é uma prática pedagógica que se apoia em conhecimentos científicos, sem pretender ela própria ser uma ciência. Brito (2006), por sua vez, empregou algumas ideias de Parlebas para tratar de ações específicas da aula de Educação Física escolar desde a competência motriz. Mosquera (2010, p. 120), ao investigar as tendências mais significativas na Educação Física escolar em algumas instituições do país, concluiu que a "praxeología motriz", ou “ciência da ação motriz", foi uma das 5 perspectivas presentes nas aulas, basicamente desde a ideia da sociomotricidade (apesar de ser a menos expressiva dentro das categorias descritas pelo autor). Desde essa linha, os professores estudados por Mosquera argumentaram que usam a concepção no “[...] desarrollo de valores como la solidaridad, el compañerismo, el control de la agresividad, la integración y el fortalecimiento de grupo". ${ }^{7}$

Apesar da influência de Parlebas, algumas críticas foram direcionadas a sua proposta. Sobre o objeto proposto por ele, "el ser que se mueve", dentro do contexto da conduta motriz, o Editorial da revista "Lúdica Pedagógica" (1996, p. 6) entendia que o autor não desenvolvia o tema com detalhes, o que acabava reforçando o que ele mesmo criticava:

\footnotetext{
${ }^{7}$ Mais autores recorreram à teoria de Parlebas para desenvolver outras temáticas. Muñoz (1992-3, p. 50) empregou o conceito de transferência para caracterizar que esse processo ocorre "[...] cuando la ejecución de una habilidad modifica, de manera positiva o negativa, la realización de una actividad antigua". Arias (2001, p. 66), por sua vez, utilizou a teoria do autor para "Proponer un modelo de intervención para la formación de los profesionales de la Educación Física en el área de la iniciación deportiva con la aplicación de la teoría de los sistemas a través de la implementación de un programa basado en la praxiología motriz".
} 
Sobre la especificidad Parlebas se interroga: ‘PPosee la Educación Física un objeto especifico?' A lo cual responde: 'La concepción que descansa sobre la noción de movimiento nos parece indiscutiblemente rebasada. La Educación Física debe cumplir su revolución copernicana, es decir, aceptar cambiar de centro; debe desligarse del movimiento para llevar su atención hacia el Ser que se mueve'. Profunda aspiración, loable empresa, noble reto, desgarrador empeño, 'radical' toma de posición. Ojalá algún día se lo tomara en serio, incluido el mismo Parlebas, quien con su 'conducta motriz' se sale por la tangente para caer en lo mismo que critica.

Na mesma direção, Diaz (2010, p. 139) argumentou a respeito do conceito de motricidade em Parlebas, que "[...] no solo continua la dicotomía inteligencia-motricidad (en un sentido que podríamos llamar neo-cartesiano del mismo) sino que afirma la especialización en la motricidad como propósito fundamental de un tipo de labor relacionado con el 'hacer mover a otro' (motricista)"; em outras palavras, uma "mera operatividad del movimiento" (DIAZ, 2010, p. 141).

\section{JOSÉ MARÍA CAGIGAL: o homem em movimento}

"Una propuesta reconocida en este recorrido de teorías de la Educación Física es la de José María Cagigal" (WILCHES, 2012, p. 119). A referência a Cagigal aparece, segundo Wilches (2012), como outro dos discursos para outorgar cientificidade ao campo. A propósito disso, a revista "Educação Física y Deporte” publicou, em 1984, o texto do autor, “¿La Educación Física, ciencia?". No artigo, entendia-se que, apesar da diversidade de perspectivas no campo, existe uma “[...] precisión cada vez más unánime del objeto de la ciencia que nos ocupa, el hombre en movimiento o capaz de movimento [...]" (CAGIGAL, 1984, p. 56). Nessa publicação, o autor conclui que

La ciencia del hombre en movimiento se va configurando cada vez más dentro de las ciencias humanísticas, gracias quizá a un colectivo instinto de defensa por el cual el hombre inconscientemente tiende a defender su propia humanidad y busca instintivamente nuevos apoyos en nuevas posturas. El hombre en movimiento, el hombre activo físicamente, el hombre deportivo, puede ser objeto de un nuevo entendimiento científico merced al cual se pueden descubrir importantes medios de ayuda humanística. Por eso, por ser un posible campo de ayuda, debe ser enmarcada esta ciencia entre las educativas (CAGIGAL, 1984, p. 58)

Como pode se notar, além da referência ao discurso sobre a cientificidade da Educação Física, alocando-a, inclusive, no âmbito das humanidades, o autor foi importante na defesa do caráter pedagógico da disciplina. Assim,

El aporte del profesor Cagigal estaba relacionado con su perspectiva sobre la Educación y la Educación Física, sobre el Deporte, y sobre la Cultura Física, 
basado en sus distintas obras y artículos. Fue un momento en el que la Teoría de la Educación Física colombiana acogió sus ideales humanistas, lo que le permitió encontrar una relación con la Filosofía, la Antropología y la Sociología, además de ubicarse de manera fundada como una disciplina de carácter pedagógico (WILCHES, 2012, 176).

Pinillos (2003) e Facultad (2002) também o destacaram como um dos mais influentes pensadores na Universidade Pedagógica Nacional, na década de 1980, em sua busca por fundamentação teórica para a disciplina.

El carácter humanístico de Cajigal impresiona. Se le conoce personalmente en sus visitas y cursos en Bogotá, organizados por el profesor Héctor Peralta y el Comité Nacional de la Federación Internacional de Educación Física (FIEP). Las propuestas de Cajigal se acogen y se critican las anteriores, por su falta de pedagogía humanista (FACULTAD, 2002, p. 4).

Considerando tal interpretação, um dos Editoriais (EDITORIAL, 1982, p. 1) da revista "Educación Física y Deporte" é dedicado a explorar o pensamento do autor em relação a disciplinas escolares que, para Gagigal, eram humanistas, como a Educação Física e as Artes, as quais deveriam se converter na "columna vertebral de la escuela del futuro", devido à "crisis de la Escuela Tradicional basada en la acumulación y transmisión de información".

O mesmo autor, em outro Editorial daquela revista (1983, p. 1), vale-se de Cagigal para fazer uma reflexão sobre a necessidade que o ser humano tem do movimento e do papel da Educação Física diante desse imperativo. Assim,

Las ciudades contemporáneas restringen cada vez más el movimiento. Los niños no corren, no saltan, no juegan. Los adultos sufren la enfermedad del motorismo o 'motorosis' el movimiento por medio del motor, de la máquina. El alejamiento de la naturaleza del movimiento, producen un hombre subnormal, un cuerpo parásito fuente de achaques y disfunciones. Como dice Cagigal: 'Hay un generalizado analfabetismo del movimiento en los países industrializados. La compensación está en la actividad física. La gran tarea de la Educación Física moderna es la de recuperar la riqueza del hombre y por consiguiente su equilibrio intelectual y físico motriz'.

Em direção semelhante, Calderón (2006, p. 87) trabalhou com a ideia de Cagigal em favor de um "esporte social”, que acolhe grandes massas e que estimula a "[...] creatividad, formación, salud, libertad, participación social, diversión, participación, descanso y ocupación voluntaria”, diferente do esporte de competição, restrito a uma elite motora.

Gracia (1996, p. 1) discutiu a necessidade de definir a finalidade da Educação Física desde o foco na (trans)formação do ser humano, propondo, para isso, operar com o objeto de estudo 
sugerido por Cagigal: o homem em movimento ou capaz de movimento e as relações sociais que se desenvolvem nessa ação, "[...] lo cual permite plantear que la Educación Física debe ser orientada y desarrollada en dos grandes sentidos: como factor de desarrollo evolutivo, y como medio de expresión y comunicación socio-cultural". Ao mesmo tempo, o autor entendeu que tal proposta ajudaria a superar a hegemonia do esporte na área. Chinchilla (2005), anos depois, afirmou que a teoria de Cagigal ofereceu um significativo aporte para a superação da abordagem orgânica do corpo baseada no enfoque fisiológico e mecanicista. Na mesma linha, Correa e Martínez (2006, p. 36) usaram o autor espanhol para discutir o papel da Educação Física na formação integral dos sujeitos, apontando que a disciplina

Ha llegado a considerarse en sí misma como educación integral en tanto ella se ocupa del desarrollo del individuo en sus dimensiones: físicas, psicomotrices, efectivas, cognoscitivas, estéticas y éticas, como lo expresa José María Cagigal, quien considera a la educación física como el más básico modo natural de educar al niño, de una manera globalizada.

De acordo com o depoimento de E5 (2017), o autor espanhol tinha uma formação muito ampla, principalmente desde a Filosofia, sendo bastante impactante sua perspectiva teórica, o que o levou à Colômbia algumas vezes para palestras e outras atividades. ${ }^{8}$ Justamente a partir dessa densidade teórica, o professor E5 (2017) confessou certa dificuldade do campo para levar essa teoria à prática. Nessa linha, advertiu E11 (2017) que considerava que o autor tinha sido bastante mal-usado e mal interpretado na Colômbia, sobretudo desde o conceito de "deporte educativo", basicamente pela aplicabilidade em contextos que, segundo a entrevistada, não correspondiam à proposta do autor.

Além de "deporte educativo", Wilches (2012) atribuiu ao autor o conceito de "Educação Física de base", bastante utilizado, também, no contexto colombiano. Explicou tal concepção informando que:

Reconoce, el eminente profesor español, el surgimiento de enfoques y movimientos de Educación Física que considera fundamentales, entre los cuales cita a Le Boulch, Souviran, Picq, Vayer y Medau. Y plantea (1968: 10) la posibilidad de una asignatura denominada 'Educación Física de Base', con un sentido nuevo, el de preocuparse por los orígenes físico-educativos de los esquemas académicos. Tal vez, sea una forma inicial de propuesta de incorporar un espacio de teorización sobre la Educación Física en la formación académica (WILCHES, 2012, p. 122).

\footnotetext{
${ }^{8}$ A este respeito, Morales $(1990,1996)$ informa que as considerações de Cagigal foram importantes, na Colômbia, para a reflexão filosófica sobre o corpo e o movimento como as realidades antropológicas fundantes da Educação Física. No mesmo caminho, Pachón e Perafán (2013, p. 124) entendem que as "bases antropofilosóficas" da obra de Cagigal chamada "Cultura intelectual y cultura física', de 1979, foi fundamental para a compreensão da "[...] particularidad de la Educación Física como disciplina que nace para ser enseñada”.
} 
A partir da discussão sobre o objeto de estudo da Educação Física, Bolívar (1991) questionou a especificidade da disciplina considerando o objeto de estudo que o autor propunha:

El profesor José María Cagigal, en un importante artículo que recoge diversidad de argumentaciones, defiende el carácter científico de la educación física, destacando que su objeto de estudio es: 'El hombre en movimiento o capaz de movimiento, y las relaciones sociales creados a partir de esta aptitud o actitud'. Lo que no es, preciso, ni delimitado, ni explicado en su escrito, pareciendo ser más bien una generalización tan amplia, que bien podría ser susceptible de tratamiento por casi todas las ciencias (BOLÍVAR, 1991, p. 13).

Ao mesmo tempo em que questionou o objeto de estudo proposto por Cagigal, Bolívar (1991) concordava com o autor sobre o fato de que a diversidade de objetos existentes no campo era um problema para a definição acadêmica da Educação Física.

\section{CONSIDERAÇÕES FINAIS}

O objetivo deste artigo foi dar visibilidade a algumas apropriações que atores e autores da Educação Física colombiana, a partir dos anos 1970, fizeram de tendências internacionais desse campo. A análise levou em consideração perspectivas de Educação Física oriundas de Cuba, da Alemanha, da Espanha e da França. A ideia não foi a de descrever, pormenorizadamente, cada uma das posições resenhadas (seus conceitos principais, influências teóricas, etc.), tarefa que outros colegas no campo já realizaram, ${ }^{9}$ mas identificar onde, como e por que aquelas referências internacionais foram sendo incorporadas por autores, atores e instituições formativas no país andino.

Os resultados indicaram as apropriações realizadas pelos entrevistados e suas manifestações nos artigos publicados nas revistas investigadas, sendo tais iniciativas importantes por contribuírem, cada qual a sua maneira, para se pensar e problematizar a tradição da Educação Física colombiana, ao mesmo tempo em que ofereciam alternativas a problemas e questões que acometiam o campo acadêmico após os anos 1970, como a crescente esportivização da disciplina, a cientifização almejada, o debate a respeito do objeto de estudo e a definição da identidade acadêmica e profissional do campo. Em maior ou menor medida, as ideias dos autores antes mencionados impactaram nas instituições formadoras da Educação Física, no debate teórico do campo, na promulgação de leis relacionadas à disciplina, etc. Hoje, todavia, eles já não têm o peso que tiveram

\footnotetext{
${ }^{9}$ Este é, por exemplo, o caso de Gallo (2010). Apesar disso, seu exercício analítico sobre o trabalho de Gagigal, Parlebas, Le Bouch e Manuel Sérgio não se preocupou em situar o impacto desses autores no campo da Educação Física na Colômbia.
} 
outrora no campo acadêmico, que é caracterizado por um crescente pluralismo teórico. Isso não significa, contudo, que referências a eles não possam ainda ser encontradas nas revistas e, mesmo, que estejam vivas nas memórias de muitos professores da área, como os aqui entrevistados.

Às perspectivas aqui resenhadas poderiam juntar-se outras. O conceito de Ciência(s) de Esporte, vinculado ao convênio colombo-alemão, é um deles. Tratamos do impacto que teria provocado no campo em outras publicações (EUSSE; ALMEIDA; BRACHT, 2018, 2019a, 2019b).

Outra é representada por Ommo Gruppe, cujo nome é encontrado na literatura estudada e pelos entrevistados E2 (2016), E5 (2017), E7 (2017), E10 (2017) e E12 (2017), ${ }^{10}$ que o reconhecem como uma importante influência para o campo teórico da Educação Física colombiana. Outro autor que merecia uma análise é Manuel Sérgio. Entre os entrevistados, alguns vão destacar a influência de seus conceitos em alguns acadêmicos do campo, em especial suas considerações sobre a motricidade humana; outros, por sua vez, consideram que suas ideias não tiveram muito impacto. Pouco influente teria sido, nesse contexto, a sua tese da existência de uma nova ciência, por ele chamada de "Ciência da Motricidade Humana". Tais exercícios analíticos, todavia, constituem motivações para futuras investigações.

\section{REFERÊNCIAS}

ALMEIDA, Felipe Quintão; SILVA, Angélica Caetano; EUSSE, Karen Lorena Gil. A Educação Física na educação infantil no Brasil e na Colômbia: diálogos introdutórios. Motrivivência, v. 30, n. 53, 2018, p. 248266.

ARBOLEDA, Rubiela. Cultura física y embarazo. Educación Física y Deporte, Medellín,v. 12, n. 1-2, p. 61-81, 1990.

ARIAS, Elkin Arias. La formación del profesional de Educación Física, en el área de iniciación deportiva, utilizando la teoría de sistemas y la praxiología motriz. Educación Física y Deporte, Medellín,v. 21, n. 22 p. $\underline{63-69,2001 .}$

BENJUMEA, Margarita María. La motricidad, corporeidad y pedagogía del movimiento en educación física: un asunto que invita a la transdisciplinariedad. In: CONGRESO CIENTÍFICO

LATINO-AMERICANO. 3.; SIMPÓSIO LATINO-AMERICANO DE MOTRICIDAD HUMANA. 1., 2004. Disponível em: http://viref.udea.edu.co/contenido/pdf/04 la motricidad corporeidad.pdf. Acesso em: 20 out. 2016.

BOLÍVAR, Carlos. Educación Física: aproximación epistemológica. Educación Física y Deporte, Medellín, v. 13, n. 1-2, p. 9-21, 1991.

BRITO, Luis Felipe. Edificación de la competencia motriz y conquista de las realizaciones personales. Lúdica Pedagógica, Bogotá, v. 2, n. 11, p. 96-107, 2006.

${ }^{10}$ E12 (2017) foi, inclusive, orientado por Gruppe, na Alemanha. 
CAGIGAL, José María. ¿La Educación Física, ciencia? Educación Física y Deporte, Medellín,v. 6, n. 2-3, p. 49-58, 1984.

CALDERÓN, Alberto García. Concepciones de los profesores de Educación Física sobre el deporte: de la hegemonía a la utopía. Lúdica Pedagógica, Bogotá, v. 2, n. 11, p. 84-95, 2006.

CALENDARIO. Educación Física y Deporte, Medellín,v. 10, n. 1-2, p. 106-116, 1988.

CHINCHILLA, Víctor Jairo. Un editorial fuera de lugar. Lúdica Pedagógica, Bogotá, v. 2, n. 12, p. 1-4, 1998.

CHINCHILLA, Víctor Jairo. Educación Física en el proceso de modernización. Lúdica Pedagógica, Bogotá, v. 1, n. 7, p. 1-16, 2002.

CHINCHILLA, Víctor Jairo. Elementos sobre epistemología y enseñanza de la Educación Física. Lúdica Pedagógica, Bogotá, v. 2, n. 10, p. 104-112, 2005.

CORREA, Martha Ibette; MARTÍNEZ, Nelly Teresa. El pensamiento del profesor de Educación Física: un acercamiento a las prácticas educativas institucionales. Lúdica Pedagógica, Bogotá, v. 2, n. 11, p. 34-51, 2006.

EDITORIAL. Editorial (preliminares). Educación Física y Deporte, Medellín, v. 4, n. 1, p. 1, 1982.

EDITORIAL. Editorial (preliminares). Educación Física y Deporte, Medellín, v. 5, n. 1, p. 1, 1983.

EDITORIAL. Editorial (preliminares). Lúdica Pedagógica, Bogotá, n. 2, p. 5-6, 1996.

EUSSE, Karen Lorena Gil.; ALMEIDA, Felipe Quintão.; BRACHT, Valter. Convênio Colombo-Alemão (1973-1984): a esportivização da Educação Física colombiana? Revista Da Alesde, 9, 106-118, 2018. Recuperado de https://revistas.ufpr.br/alesde/article/view/61272/35953

EUSSE, Karen Lorena Gil.; ALMEIDA, Felipe Quintão.; BRACHT, Valter. “Esportivização” da Educação Física colombiana: a "herança" do convênio Colombo-Alemão nas páginas da revista Educación Física y Deporte. Revista Brasileira de Ciências do Esporte, v. 41, n. 4, p. 437-443, 2019a.

EUSSE, Karen Lorena Gil.; ALMEIDA, Felipe Quintão.; BRACHT, Valter. Cientifização da Educação Física colombiana: a marca do Convênio Colombo-Alemão. In:

GOMES, Ivan Marecelo., GALAK, Eduardo., ALMEIDA, Felipe Quintão.; MORENO, William Gómez (Org). Sentidos y prácticas sobre la educación y los usos del cuerpo: Intercambios académicos entre Argentina, Brasil, Colombia y Uruguay. La Plata/Vitória: Universidad de La Plata/Edufes. 2019b. p. 198213.

EUSSE, Karen Lorena Gil. Tradição, crítica e renovação na Educação Física colombiana. 2020. Tese (Doutorado em Educação Física) - Programa de Pós-Graduação em Educação Física, Vitória, 2020.

FACULTAD Educación Física. En busca de los contenidos de la Educación Física. Lúdica Pedagógica, Bogotá, v. 1, n. 7, p. 1-6, 2002.

GALLO, Luz Elena. Los discursos de la educación física contemporánea. Bogotá: Kinesis, 2010.

GALLO, Luz Elena; URREGO, León Jaime. Estado de conocimiento de la Educación Física en la investigación educativa. Perfiles Educativos, México, N. XXXVII, 2015.

GRACIA, Álvaro José. Concepción de Educación Física. Lúdica Pedagógica, Bogotá, n. 2, p. 1-6, 1996. 
GRACIA, Álvaro José. La psicomotricidad como alternativa de reivindicación de la importancia del cuerpo y el movimiento para el desarrollo humano. Lúdica Pedagógica, Bogotá, n. 2, p. 123-131, 2006.

MOLINA, Victor; OSSA, Arley. ¿Cuál Educación Física para América Latina?. Espacio Abierto, v. 18, n. 1, p. 65-75, 2009.

MORALES, Leonel Reina. Elementos para una aproximación al trabajo teórico de la Educación Física en Colombia. Educación Física y Deporte, Medellín, v. 12, n. 1-2, p. 9-28, 1990.

MOSQUERA, Libardo Mateus. Tendencias de la Educación Física escolar. Análisis desde la confrontación. Lúdica Pedagógica, Bogotá, v. 2, n. 15, p. 116-121, 2010.

MUÑOZ, Armando. Principios de la transferencia: clave para el desarrollo y el aprendizaje motriz.

Educación Física y Deporte, Medellín, v. 14-15, p. 43-55, 1992-93.

PACHÓN, José Orlando; PERAFÁN, Gerardo Andrés. A. El conocimiento profesional del profesor de Educación Física. Lúdica Pedagógica, Bogotá, v. 2, n. 18, p. 123-131, 2013.

PARLEBAS, Pierre. Didáctica y lógica de las actividades físicas deportivas. Educación Física y Deporte, Medellín, v. 14-15, p. 9-26, 1992-93.

PATIÑO, Rosa Yurany; DÍAZ, Freddy Alexander. Las prácticas de enseñanza de los profesores del área de la Educación Física, la Recreación y el Deporte. Educación Física y Deporte, Medellín, v. 28, n. 2, p. 119126, 2009.

PINILLOS, Jesus Maria. La Educación Física y el deporte en Colombia. Una oposición de discursos en el periodo comprendido entre 1968 y 1991. 2003. Dissertação (Mestrado em Educação) - Facultad de Educación da Universidade de Antioquia, Medellín, 2003.

PINILLOS, Jesus Maria. La pedagogía y la motricidad humana, una condición de posibilidad para la construcción de una episteme de la Educación Física en la perspectiva del desarrollo humano en Colombia. Lúdica Pedagógica, Bogotá, v. 2, n. 12, p. 19-30, 2007.

PINILLOS, Jesus Maria. La constitución del campo de la Educación Física en Colombia en el periodo comprendido entre 1968 y 1991. História do Esporte, Rio de Janeiro, v. 4, n. 2, p. 1-23, 2011.

SÁNCHEZ, Beatriz Córdova; BARROSO, Glória Rodríguez. La formación del profesional de la Cultura Física y el Deporte: experiencia cubana. In: SILVA, Ana Márcia; BEDOYA, Víctor Molina. Formação profissional em Educação Física na América Latina: encontros, desafios e perspectivas. Jundiaí: Paco Editorial, 2015. P. 119-148.

URIBE, Iván Darío. Motricidad infantil y desarrollo humano. Educación Física y Deporte, Medellín, v. 20, n. 1,p. 91-95, 1998.

VACA. Ángel Humberto. Historia del alma máter de la Educación Física colombiana. Santa Fe de Bogotá: Universidad Pedagógica Nacional, 1998.

WILCHES, Daniel Oliveros. ¿Qué señalan los indicadores de logros en Educación Física?. Lúdica Pedagógica, Bogotá, v. 1, n. 6, p. 20-27, 2001.

WILCHES, Daniel Oliveros. Ideas influyentes en la teoría de la Educación Física de la Facultad de Educación Física de la Universidad Pedagógica Nacional (Bogotá) entre 1975 y 2000. 2012. Teses (Doutorado em Ciencias de la Actividad Física y el Deporte) - Departamento de Educación Física y Deportes da Universidad de León, León-España, 2012.WILCHES, Daniel Oliveros; 
TUERO, Concepción; ÁLVAREZ, Eduardo. Ideas influyentes en la Teoría de la Educación Física de la Facultad de Educación Física de la Universidad Pedagógica Nacional entre 1975 y 2000. Educación Física y Deporte, Medellín, v. 31, n. 2, p. 1033-1043, 2012.

\section{Entrevistas}

E1. Entrevista concedida à pesquisadora, Medellín, 2016.

E2. Entrevista concedida à pesquisadora, Medellín, 2016.

E3. Entrevista concedida à pesquisadora, Medellín, 2016.

E4. Entrevista concedida à pesquisadora, Bogotá, 2017.

E5. Entrevista concedida à pesquisadora, Bogotá, 2017.

E7. Entrevista concedida à pesquisadora, Bogotá, 2017.

E8. Entrevista concedida à pesquisadora, Bogotá, 2017.

E9. Entrevista concedida à pesquisadora, Medellín, 2017.

E10. Entrevista concedida à pesquisadora, Medellín, 2017

E11. Entrevista concedida à pesquisadora, Medellín, 2017

E12. Entrevista concedida à pesquisadora, Medellín, 2017.

E13. Entrevista concedida à pesquisadora, Cali, 2017.

E14. Entrevista concedida à pesquisadora, Montería, 2017.

E15. Entrevista concedida à pesquisadora, Neiva, 2018.

\section{NOTAS DO AUTOR}

\section{FINANCIAMENTO}

A investigação foi financiada com bolsa de Doutorado da FAPES (processo 71524754).

CONSENTIMENTO DE USO DE IMAGEM - Não se aplica

\section{APROVAÇÃO DE COMITÊ DE ÉTICA EM PESQUISA}

O projeto foi submetido no comitê de humanidade da UFES, registrado sob o número 0545881820000552 e o parecer de aprovação teve o número 344294.

CONFLITO DE INTERESSES - Não se aplica

\section{LICENÇA DE USO}

Os autores cedem à Motrivivência - ISSN 2175-8042 os direitos exclusivos de primeira publicação, com o trabalho simultaneamente licenciado sob a Licença Creative Commons Attribution Non-Comercial ShareAlike (CC BY-NC SA) 4.0 International. Esta licença permite que terceiros remixem, adaptem e criem a partir do trabalho publicado, desde que para fins não comerciais, atribuindo o devido crédito de autoria e publicação inicial neste periódico desde que adotem a mesma licença, compartilhar igual. Os autores têm autorização para assumir contratos adicionais separadamente, para distribuição não exclusiva da versão do trabalho publicada neste periódico (ex.: publicar em repositório institucional, em site pessoal, publicar uma tradução, ou como capítulo de livro), com reconhecimento de autoria e publicação inicial neste periódico, desde que para fins não comerciais e compartilhar com a mesma licença.

\section{PUBLISHER}

Universidade Federal de Santa Catarina. Programa de Pós-Graduação em Educação Física. LaboMídia - Laboratório e Observatório da Mídia Esportiva. Publicado no Portal de Periódicos UFSC. As ideias expressadas neste artigo são de responsabilidade de seus autores, não 
representando, necessariamente, a opinião dos editores ou da universidade.

\section{EDITORES}

Mauricio Roberto da Silva, Giovani De Lorenzi Pires, Rogério Santos Pereira.

\section{HISTÓRICO}

Recebido em: 29 de março de 2020.

Aprovado em: 21 de maio de 2020. 